\title{
POLÍTICAS PÚBLICAS EDUCACIONAIS DE GÊNERO E DIVERSIDADE SEXUAL: AVANÇOS E RETROCESSOS
}

\author{
Isabela Maria Oliveira Catrinck (Unimontes)* \\ https://orcid.org/0000-0001-6843-8592 \\ Sandy Aparecida Barbosa Magalhães (Unimontes)** \\ https://orcid.org/0000-0003-3656-8653 \\ Zilmar Santos Cardoso (Unimontes) ${ }^{* * *}$ \\ https://orcid.org/0000-0001-6101-2310
}

\section{RESUMO}

0 presente estudo encontra-se inserido no campo da educação e tem por tema as Políticas Públicas Educacionais em Gênero e Diversidade Sexual, suas conquistas e seus retrocessos. 0 estudo objetiva analisar as principais Políticas Públicas Educacionais de Gênero e Diversidade Sexual, evidenciando suas ascensões frente ao avanço conservador do Movimento Escola Sem Partido. Para alcançar o objetivo posto, foi realizada uma pesquisa bibliográfica cujo processo investigativo apresenta como referencial teórico-metodológico os princípios da pesquisa qualitativa com caráter descritivo. Os estudos nesse trabalho apontaram que a escola, como instituição social representativa da sociedade e de formação de cidadãos capazes de atuarem conscientemente e sem preconceitos, necessita se apropriar de conhecimentos sobre as questões de igualdade de gênero e diversidade sexual. Para tanto, torna-se importante que as políticas públicas educacionais se concretizem como políticas de Estado, e não como políticas de governo que visam atender aos anseios e projeções de determinados grupos sociais conservadores, ocasionando assim em retrocessos nos mínimos avanços conquistados na elaboração e implantação de Políticas Públicas que visam garantir de forma efetiva uma dinâmica educacional inclusiva. Palavras-chave: Políticas públicas educacionais. Gênero. Diversidade sexual. Escola sem Partido.

\section{ABSTRACT \\ PUBLIC EDUCATIONAL POLITICS ON GENDER AND SEXUAL DIVERSITY: ADVANCES AND SETBACKS}

The following study is inserted in the education area and has as its theme the

\footnotetext{
* Mestranda em Educação pela Universidade Estadual de Montes Claros (Unimontes). E-mail: isabelac.educacao@gmail.com

** Mestranda em Educação pela Universidade Estadual de Montes Claros (Unimontes). E-mail: Sandy.magalhaes91@gmail.com

*** Doutora em Ciências Sociais pela Universidade Estadual do Rio de Janeiro (UERJ). Professora do Programa de Pós-Graduação em Educação da Universidade Estadual de Montes Claros (Unimontes). E-mail: zilmar.santos@unimontes.br
} 
Public Educational Politics in Gender and Sexual Diversity, its achievements and its setbacks. The study aims to analyze the main Public Educational Policies of Gender and Sexual Diversity, evidencing their ascension in face of the conservative advance of the School Without Party Movement. To achieve the stated objective, a bibliographic research was carried out whose investigative process presents the principles of qualitative research with a descriptive character as a theoretical-methodological framework. The studies in this work pointed out the school needs to appropriate knowledge on issues of gender equality and sexual diversity as a social institution representative of society and of citizens formation capable of acting consciously and without prejudice. Therefore, it is important that public educational policies become concrete as State policy and not as government policies that aim to meet the desires and projections of certain conservative social groups, thus causing setbacks in the minimum advances achieved in the elaboration and implementation of Public Politics which aim to effectively guarantee an inclusive educational dynamic.

Keywords: Public educational politics. Gender. Sexual diversity. School Without Party.

\section{RESUMEN}

\section{POLÍTICAS PÚBLICAS EDUCACIONALES DE GÉNERO Y DIVERSIDAD SEXUAL: AVANZOS Y RETROCESOS}

El presente estudio se encuentra inserido en el campo de la educación y ten por tema las Políticas Educacionales en Género y Diversidad Sexual, sus conquistas y sus retrocesos. El estudio objetiva analizar las principales Políticas Educacionales en Género y Diversidad Sexual, evidenciando sus ascensiones frente al avanzo conservador del Movimiento Escuela sin Partido. Para alcanzar el objetivo puesto, fue realizada una pesquisa bibliográfica cuyo proceso investigativo presenta como referencial teórico metodológico los principios de la pesquisa cualitativa con carácter descriptivo. Los estudios en ese trabajo apuntaran que la escuela, como institución social representativa de la sociedad e de formación de ciudadanos capaces de actuaren conscientemente y sin prejuicios necesita apropiarse de conocimientos sobre las cuestiones de igualdad de género $y$ diversidad sexual. Para tanto, tornase importante que las políticas públicas educacionales se concreticen como política de Estado y no como conservadores, ocasionando así retrocesos en los mínimos avanzos conquistados en la elaboración y implantación de Políticas Públicas que visan garantir de forma efectiva una dinámica educacional inclusiva.

Palabras clave: Políticas públicas educacionales. Género. Diversidad sexual. Escuela sin Partido. 


\section{Introdução}

0 presente estudo encontra-se inserido no campo da educação e tem por tema as Políticas Públicas Educacionais em Gênero e Diversidade Sexual, suas conquistas e retrocessos. Esse estudo se faz necessário em razão da importância da presença de temáticas relacionadas à discussão sobre Gênero e Diversidade Sexual no espaço escolar e na sociedade; sobretudo pelo fato de que, nas sociedades modernas, a escola desempenha um papel social privilegiado, onde se produz e se reproduz conhecimentos; espaço onde deve constituir-se também em um ambiente de formação de percepção de mundo, de consciência social, de transmissão de valores, de fomento à diversidade cultural e de formação de sujeitos críticos e ativos, aptos a desenvolverem sua cidadania.

Nesse contexto, o estudo objetiva analisar as principais Políticas Públicas Educacionais de Gênero e Diversidade Sexual, evidenciando seus retrocessos frente ao avanço conservador do Movimento Escola Sem Partido.

Para alcançar o objetivo posto, foi realizada uma pesquisa bibliográfica em que o processo investigativo apresenta como referencial teórico-metodológico os princípios da pesquisa qualitativa com caráter descritivo; para tanto, foram analisadas algumas políticas públicas, como o Programa Nacional de Direitos Humanos (PNDH), os Parâmetros Curriculares Nacionais (PCN), o Conselho Nacional de Combate à Discriminação (CNCD), o Programa Brasil sem Homofobia e a criação da extinta Secretaria de Educação Continuada, Alfabetização e Diversidade (SECAD), bem como o Movimento Social denominado Escola sem Partido (MESP).

Entendemos que a escola, na qualidade de instituição social representativa da sociedade e de responsável pela formação de cidadãos capazes de atuarem conscientemente, desprovidos de preconceitos e discriminação frente às diferenças, necessita se apropriar de conhecimentos primordiais sobre as questões de igualdade de gênero, de diversidade cultural e sexual. Para tanto se faz necessário que os profissionais da escola tenham consciência da importância de se abordar temas voltados para a sexualidade, a diversidade e a discriminação, assumindo um caráter pluralista, considerando a abrangência que caracteriza os sujeitos.

\section{Políticas Públicas Educacionais de Gênero e Diversidade Sexual}

Ao se propor avaliar o sistema educacional brasileiro no que tange a suas políticas públicas, é importante reconhecer que, a partir das duas últimas décadas do século $\mathrm{XX}$, percorreuse um rico cenário de projetos e inovações educacionais. Logo, ao pensarmos na pauta escolar e nas políticas públicas direcionadas à educação, salienta-se as inquietações com as temáticas relacionadas com a diversidade, a inclusão e a redução das desigualdades.

Nessa perspectiva, em decorrência do processo de democratização e da luta e pressão dos movimentos sociais, desde os anos 1980, afluiu no Brasil, ainda que de forma muito tímida, uma progressiva inserção de questões relacionadas às desigualdades, diversidades de gênero e sexualidade na agenda governamental. Questões que passaram a fazer parte das discussões em âmbitos educacionais por consequência da Constituição de 1988, que conforme Domingos (2016, p. 121) "representou um marco da luta pelos direitos sociais, em que o Estado assumiu o compromisso em promover o bem comum e assegurar os direitos sociais, como a educação escolar pública, gratuita, de qualidade e com gestão democrática".

Assim, essa agenda governamental buscou a implantação de políticas públicas como o Programa Nacional de Direitos Humanos (PNDH), os Parâmetros Curriculares Nacionais (PCN), o Conselho Nacional de Combate à Discriminação (CNCD), o Programa Brasil sem Homofobia e a criação da Secretaria de Educação Continuada, 
Alfabetização e Diversidade (SECAD), ações que entendemos como marco primordial na propulsão de políticas sobre diversidade sexual e gênero no campo educacional.

\section{Programa Nacional de Direitos Humanos}

O primeiro Programa Nacional em Direitos Humanos (PNDH I) foi publicado por meio do Decreto Presidencial no 1.904 , de 13 de maio de 1996 (BRASIL, 1996), tendo por fundamento as resoluções da Conferência Mundial em Direitos Humanos das Nações Unidas, realizada em 1993 na cidade de Viena. 0 documento atribuiu maior destaque à promoção e defesa dos direitos civis, mediante 228 propostas de ações governamentais, evidenciando a inquietação do Estado diante da integridade física, da liberdade e do espaço de cidadania de populações vulneráveis e com histórico de discriminação, como posto em seus objetivos, no art. $2^{\mathrm{o}}$ :

I- a identificação dos principais obstáculos à promoção e defesa dos direitos humanos no País; II- a execução, a curto, médio e longo prazos, de medidas de promoção e defesa desses direitos; III- a implementação de atos e declarações internacionais, com adesão brasileira, relacionados com direitos humanos; IV- a redução de condutas e atos de violência, intolerância e discriminação, com reflexos na diminuição das desigualdades sociais; V- a observância dos direitos e deveres previstos na Constituição, especialmente os dispostos em seu art.5; VI- a plena realização da cidadania. (BRASIL, 1996).

No que tange à temática de gênero e diversidade sexual, esse foi o primeiro documento oficial do Estado a trazer de forma expressa o termo "homossexuais" em seu texto:

Direitos Humanos são os direitos fundamentais de todas as pessoas, sejam elas mulheres, negros, homossexuais, índios, idosos, pessoas portadoras de deficiências, populações de fronteiras, estrangeiros e emigrantes, refugiados, portadores de HIV positivo, criança e adolescentes, policiais, presos, despossuídos e os que tem acesso a riqueza. Todos, enquanto pessoas, devem ser respeitados e sua integridade física protegida e assegurada. (BRASIL, 1996).

A referência também é vista dentre as ações a serem elaboradas pelo PNDH I ao tratar da proteção ao direito a vida, a segurança das pessoas e a proteção do direito ao tratamento igualitário perante a lei, como podemos observar:

5. Apoiar programas para prevenir a violência contra grupos em situação mais vulnerável, caso de crianças e adolescentes, idosos, mulheres, negros, indígenas, migrantes, trabalhadores sem-terra e homossexuais.

\section{[...]}

78. Propor legislação proibindo todo tipo de discriminação, com base em origem, raça, etnia, sexo, idade, credo religioso, convicção política ou orientação sexual, e revogando normas discriminatórias na legislação infraconstitucional, de forma a reforçar e consolidar a proibição de práticas discriminatórias existente na legislação constitucional. (BRASIL, 1996)

Aperfeiçoando o PNDH I, lançado em 1996, é elaborado em 2002, no final do mandato do Presidente Fernando Henrique Cardoso, o Plano Nacional de Direitos Humanos II (PNDH II). É perceptível no novo documento a preocupação do governo em propor ações com maior direcionamento quantitativo e qualitativo à questão da "orientação sexual". 0 PNDH II apresenta uma seção específica sobre orientação sexual, diferindo do documento anterior, que expunha apenas duas propostas de ação fixadas em outros temas. 0 documento também inova ao explicitar em seu texto a transexualidade, além de apresentar propostas para a regulamentação da cirurgia de "redesignação de sexo" e a alteração no documento civil (BRASIL, 2002).

Ao que compete à Educação, o PNDH II orienta que, em relação à formação docente, é necessário "promover a compreensão e a consciência ética sobre as diferenças individuais e a eliminação de estereótipos depreciativos em relação aos GLTTB"1 (Gays, Lésbicas, Travestis, Transexuais e Bissexuais), bem como "incenti-

$\overline{1 \text { Atual LGBTQI+. }}$ 
var programas de orientação familiar e escolar para a resolução de conflitos relacionados à livre orientação sexual, com o objetivo de prevenir atitudes hostis e violentas" (BRASIL, 2002).

\section{Parâmetros Curriculares Nacionais}

Em decorrência das determinações da Constituição Federal de 1988 e da Lei de Diretrizes e Bases da Educação Nacional (LDB) de 1996, foram estabelecidos os Parâmetros Curriculares Nacionais (PCN), que foi o primeiro instrumento normativo que objetivou a inserção e oficialização do tema da sexualidade e do gênero no currículo escolar da Educação Básica.

Publicado no ano de 1997 e 1998, os PCNs tratam as questões sociais no processo educativo de forma transversal, incluindo os temas: ética, saúde, orientação sexual, meio ambiente e pluralidade cultural nas disciplinas curriculares do Ensino Fundamental. Acerca dos temas transversais, o documento define que,

[...] os Temas Transversais correspondem a questões importantes, urgentes e presentes sob várias formas, na vida cotidiana. 0 desafio que se apresenta para as escolas é o de abrirem-se para este debate. Este documento discute a amplitude do trabalho com problemáticas sociais na escola e apresenta a proposta em sua globalidade, isto é, a explicitação da transversalidade entre temas e áreas curriculares assim como em todo o convívio escolar. (BRASIL, 1997, p. 15).

É notório o avanço das políticas públicas educacionais no período de 2003 a 2010 em direção à valorização e respeito à diversidade, sobretudo com a inclusão dos Temas Transversais no currículo escolar, em destaque o tema Orientação Sexual. Indiscutivelmente, os Parâmetros Curriculares Nacionais se configuram, dentre os documentos oficiais que norteiam o currículo escolar, num importante avanço em relação ao reconhecimento de uma perspectiva de gênero e sexualidade.
A apresentação do tema transversal Orientação Sexual demonstra que desde a década de 1970 a discussão sobre a necessidade da inclusão da temática da sexualidade no currículo da escola vem sendo intensificada, e reconhece que as mudanças no comportamento dos jovens e o movimento das feministas e grupos que defendiam o controle da natalidade seriam os responsáveis por essas reivindicações (BRASIL, 1998), afirmando assim a importância dos movimentos sociais na conquista de políticas públicas educacionais,

Vianna e Unbehaum (2006) pontuam que os PCNs retratam o mais importante avanço em relação à legitimação de uma perspectiva de gênero nas políticas educacionais. Esse documento apresenta o Tema Transversal Orientação Sexual de forma ampla, com entendimentos de que:

Ao tratar do tema Orientação Sexual, busca-se considerar a sexualidade como algo inerente à vida e à saúde, que se expressa desde cedo no ser humano. Engloba o papel social do homem e da mulher, o respeito por si e pelo outro, as discriminações e os estereótipos atribuídos e vivenciados em seus relacionamentos, o avanço da AIDS e da gravidez indesejada na adolescência, entre outros, que são problemas atuais e preocupantes. (BRASIL, 1997, p. 287).

Em relação ao termo Orientação Sexual nos PCNs, Figueiró (2001) questiona essa expressão, já que a orientação sexual diz mais sobre a sexualidade do sujeito em relação à sua identidade sexual, que vai sendo formada ao longo da infância, e como o indivíduo se comporta ao longo de sua vida. Assim, Figueiró (2001, p. 145), considera que, no contexto do documento, o

[...] termo educação sexual é mais adequado, na medida em que se abre espaço para que a pessoa que aprende seja considerada sujeito ativo do processo de aprendizagem e não mero receptor de conhecimentos e/ou de orientações, como sugerem as outras terminologias: orientação, informação, instrução.

Embora sejam importantes as contribuições do Tema Transversal Orientação Sexual nos 
PCNs, para a legitimidade da abordagem do conteúdo no currículo escolar e seu notável aporte no tocante às políticas públicas direcionadas a gênero e sexualidade, ainda há certa discrepância no que de fato consiste a Educação Sexual. 0 conteúdo que se refere a gênero está restrito ao tópico Orientação Sexual, contudo as questões relacionadas ao gênero deveriam ainda transpor os demais temas transversais. Outro ponto que se evidencia é o fato de que ao tratar gênero e sexualidade, esses temas são associados fundamentalmente com a saúde, limitando a uma abordagem estritamente biológica e heteronormativa, tratando o tema com um caráter informativo, como podemos observar no volume 10 do tema transversal Pluralidade Cultural e Orientação Sexual, ao apresentar que:

Muitas escolas, atentas para a necessidade de trabalhar com essa temática em seus conteúdos formais, incluem Aparelho Reprodutivo no currículo de Ciências Naturais. Geralmente o fazem por meio de discussão sobre reprodução humana, com informações ou noções relativas à anatomia e fisiologia do corpo humano. Essa abordagem normalmente não abarca as ansiedades e curiosidades das crianças, pois enfoca apenas o corpo biológico e não inclui as dimensões culturais, afetivas e sociais contidas nesse mesmo corpo. (BRASIL, 2001a, p. 113).

Observamos uma lacuna no currículo escolar no que se refere à temática de gênero e diversidade sexual, que não foi preenchida com a inovação pretendida pelos PCNs. As escolas brasileiras ainda apresentam espaços que são hostis às diferenças, sobretudo àquelas que não se enquadram nos padrões heteronormativos. Assim, faz-se necessária a presença do Estado por meio de políticas educacionais que visem à implantação de programas e ações respaldados por lei, a fim de assegurar a inserção dessa temática no currículo escolar, principalmente no que se refere ao processo de formação de professores, que precisam estar preparados para lidar com a diversidade que adentra às salas de aula.

\section{Conselho Nacional de Combate à Discriminação}

O Conselho Nacional de Combate à Discriminação (CNCD) foi criado pelo Ministério da Justiça por meio do Decreto no 3.952, de 04 de outubro de 2001 (BRASIL, 2001b). 0 Conselho foi constituído com o intento de atuar na proposta e acompanhamento de Políticas Públicas implicadas na defesa dos direitos sociais e individuais de sujeitos que sofreram discriminação racial ou outras formas de intolerância. A partir do ano de 2005, mediante o Decreto no 5.397 (BRASIL, 2005), o CNCD passa a ser vinculado a Secretaria Especial de Direitos Humanos da Presidência da República.

Conforme consta em seu Regimento Interno, cabe ao Conselho a incumbência de formular e propor as diretrizes de atuação do governo direcionadas ao combate à discriminação e à promoção e defesa dos direitos. É da sua competência participar na criação de critérios e parâmetros de ação governamental, como também revisar e monitorar ações, prioridades, prazos e metas do Plano Nacional de Promoção da Cidadania e Direitos Humanos de Lésbicas, Gays, Bissexuais, Travestis e Transexuais (PNLGBT). Em 2004, por meio das atividades do CNCD e de entidades organizadas da sociedade civil, foi apresentado o Programa Brasil sem Homofobia.

\section{Programa Brasil sem Homofobia e a Secretaria de Educação Continuada, Alfabetização e Diversidade (SECAD)}

O Programa Brasil sem Homofobia foi lançado em 2004, em decorrência de uma sucessão de discussões entre o Governo Federal e a sociedade civil organizada, objetivando promover a cidadania e os direitos humanos de LGBTQ+, apoiado na equiparação de direitos e no combate à violência e à discriminação. Visando 
alcançar esse objetivo, o Programa se constitui por diferentes ações voltadas para

[...] a) apoio a projetos de fortalecimento de instituições públicas e não-governamentais que atuam na promoção da cidadania homossexual e/ou no combate à homofobia; b) capacitação de profissionais e representantes do movimento homossexual que atuam na defesa de direitos humanos; c) disseminação de informações sobre direitos, de promoção da autoestima homossexual; e d) incentivo à denúncia de violações dos direitos humanos do segmento GLTB. (BRASIL, 2004, p. 11).

No que se refere à Educação, dentre as propostas de ações, observamos a presença de um tópico específico destinado a essa temática, intitulado "Direito à Educação: promovendo valores de respeito à paz e à não discriminação por orientação sexual", constituído por atividades que buscam

Fomentar e apoiar curso de formação inicial e continuada de professores na área da sexualidade; Formar equipes multidisciplinares para avaliação dos livros didáticos, de modo a eliminar aspectos discriminatórios por orientação sexual e a superação da homofobia; Estimular a produção de materiais educativos (filmes, vídeos e publicações) sobre orientação sexual e superação da homofobia; Apoiar e divulgar a produção de materiais específicos para a formação de professores; Divulgar as informações científicas sobre sexualidade humana; estimular a pesquisa e a difusão de conhecimentos que contribuam para o combate à violência e à discriminação de GLTB; Criar o Subcomitê sobre Educação em Direitos Humanos no Ministério da Educação, com a participação do movimento de homossexuais, para acompanhar e avaliar as diretrizes traçadas. (BRASIL, 2004, p. 22-23).

Ou seja, o ponto central do Programa na esfera escolar é contribuir para a reorganização comportamental dos profissionais da educação, desde o corpo administrativo ao docente, para o acolhimento da diversidade presente no contexto social atual que adentra aos muros da escola.

A partir do ano de 2003 o governo federal criou várias secretarias voltadas para o reconhecimento da diversidade, a promoção da igualdade e o enfrentamento do preconceito e da discriminação. São elas: Secretaria Especial para Mulheres (SPM); Secretaria Especial de Direitos Humanos (SEDH); Secretaria de Educação Continuada, Alfabetização e Diversidade (SECAD) e Secretaria Especial de Políticas de Promoção da Igualdade Racial (SEPPIR) (BRASIL, 2009). O Ministério da Educação (MEC) reconhecia que, para atingir um modelo democrático de escola, era necessário efetivar a justiça social e o pleno exercício da cidadania dos sujeitos, assim como aqueles pertencentes aos grupos LGBTQ+. Dessa forma, no período do governo de Lula (2003-2010), a diversidade passou a ocupar cadeira central na agenda governamental, assim o MEC atuou na promoção de uma Educação Inclusiva, direcionada aos direitos humanos e à diversidade, em prol de uma educação que alcançasse os padrões de qualidade,

[...] além de oferecer a necessária formação científica, cultura e humanista, é aquela que valoriza o diálogo com o outro e o convívio pacífico e respeitoso de todas as diferenças, de modo a fazer com que elas não sejam motivo de inferiorização, silenciamentos, constrangimentos, insultos e agressões. (BRASIL, 2008, p. 18).

Foi fundamentado nesses princípios que o MEC instituiu a Secretaria de Educação Continuada, Alfabetização e Diversidade (SECAD), sendo destinada a ela a responsabilidade de elaborar e implementar políticas educacionais que contemplassem a diversidade. Assim, a SECAD surge, em 2004, com o propósito de reduzir as desigualdades educacionais, por meio da participação de todos os sujeitos em políticas públicas, visando assegurar a ampliação do acesso à educação. Segundo Domingos (2016, p. 131), a SECAD foi instituída no governo de Lula com o propósito de "articular as ações de inclusão social com a valorização da diversidade e com destaque às demandas até então invisibilizadas e não atendidas efetivamente pelos sistemas públicos de educação, como as questões de gênero, sexualidade, raça-etnia, entre outras". 
Assim, ainda no ano de 2004, foi instituído o Programa Brasil sem Homofobia, que em seu projeto de ações propôs vários princípios norteadores para o cumprimento do direito de todos à educação, conforme preconizado na Constituição de 1988. Apresentamos duas dessas ações do programa que consideramos singulares como subsídios para implementação de políticas públicas voltadas para a inserção da temática da diversidade sexual e gênero no currículo escolar: "Elaborar diretrizes que orientem os Sistemas de Ensino na implementação de ações que comprovem o respeito ao cidadão e à não-discriminação por orientação sexual; Fomentar e apoiar curso de formação inicial e continuada de professores na área da sexualidade [...]" (BRASIL, 2004, p. 22).

Continuando na consecução da sua missão, no ano de 2007, a SECAD lança uma coletânea com diversos temas abrangendo a temática. $\mathrm{O}$ caderno 4 da coletânea, denominado Gênero e Diversidade Sexual na Escola: reconhecer diferenças e superar preconceitos, apresentou temas sobre "[...] as questões da diversidade étnico-raciais, de gênero e diversidade sexual, geracionais, regionais e culturais, bem como os direitos humanos e a educação ambiental" (HENRIQUES et al, 2007, p. 5).

Os cadernos da SECAD foram elaborados com a finalidade de documentar as suas políticas públicas educacionais de maneira informativa e formativa,

[...] sendo direcionado àqueles que precisam compreender as bases - históricas, conceituais, organizacionais e legais - que fundamentam, explicam e justificam o conjunto de programas, projetos e atividades que coletivamente compõem a política posta em andamento pela SECAD/MEC a partir de 2004. (HENRIQUES et al, 2007, p. 5).

A SECAD implantou e implementou importantes políticas públicas educacionais voltadas para temáticas da diversidade, com a oferta de cursos de formação continuada para professores da Educação Básica, Em parceira com o Fundo Nacional de Desenvolvimento da Educação (FNDE) e a Secretaria de Educação a Distância (SEED), e com o apoio da Coordenação de Aperfeiçoamento de Pessoal de Nível Superior (CAPES), a SECAD implementou a Rede de Educação para a Diversidade no âmbito da Universidade Aberta do Brasil (UAB), com o objetivo de ofertar cursos a distância de formação continuada para professores, abrangendo temas da diversidade. A Rede foi instituída em nível nacional com a participação de diversas Instituições de Ensino Superior (IES) que ofertaram os cursos propostos pela Secretaria, com o objetivo de promover a formação continuada de professores da Educação Básica em temas da diversidade, que foram: Educação na Diversidade e Cidadania, Educação Integral Integrada, Educação de Jovens e Adultos, Educação para as Relações Étnico Raciais e Gênero e Diversidade na Escola. A Universidade Estadual de Montes Claros (Unimontes) ofertou o curso Gênero e Diversidade na Escola, por meio da educação a distância, em duas edições no período de 2009 a 2010, atingindo cerca de novecentos professores da Educação Básica (CARDOSO, 2016).

0 curso Gênero e Diversidade na Escola foi ofertado no período de 2008 a 2010 por diversas IES, propondo a reflexão de temas como: Diversidade; Gênero: um preconceito importante para o conhecimento do mundo social; A importância dos movimentos sociais na luta contra as desigualdades sociais; Gênero no Cotidiano Escolar; Sexualidade: dimensão conceitual, diversidade, discriminação; Sexualidade, direitos e educação; Sexualidade no cotidiano escolar (BRASIL, 2009). A oferta desse curso pela SECAD foi uma importante política pública educacional, voltada para a implementação da discussão sobre gênero, sexualidade e orientação afetivo-sexual no currículo escolar.

Apesar de extenso, achamos importante listar as principais iniciativas implementadas pela SECAD no campo educacional que contribuíram para que os temas da diversidade adentrassem no contexto curricular: 
- Aprimoramento dos critérios relativos a gênero e relações étnico-raciais nos Editais do Programa Nacional do Livro Didático 2007 e 2008, em colaboração com a SEB/MEC. Os editais foram publicados em outubro de 2004, e as obras serão distribuídas em 2007 e 2008;

- participação na reelaboração dos Parâmetros Curriculares Nacionais do Ensino Médio (PCNEM), em colaboração com o Departamento de Ensino Médio da SEB/MEC, de modo a contemplar os temas gênero, identidade de gênero e orientação sexual. A Secad/MEC produziu, em 2005, o Caderno de Diversidades, com um capítulo que aborda questões relativas a gênero, identidade de gênero e orientação sexual. Neste: i) faz-se um histórico da inclusão dessas temáticas na educação brasileira; ii) deslindam-se os conceitos de gênero, identidade de gênero e orientação sexual e enfatizam-se seus nexos; iii) aprofunda-se a discussão sobre o currículo e tais temáticas; e iv) fazem-se recomendações;

- elaboração de estudo sobre a abordagem de gênero e orientação sexual no Plano Nacional de Educação (PNE), visando à revisão de suas metas, em atendimento ao convite do Conselho Nacional de Educação (CNE);

- construção de indicadores sobre diversidade, visando a acompanhar e avaliar os efeitos e os impactos das políticas públicas educacionais no que diz respeito a gênero e orientação sexual;

- participação na reelaboração do Plano Nacional de Educação em Direitos Humanos, de modo a garantir a inclusão das temáticas de gênero, identidade de gênero e orientação sexual. (MINISTÉRIO DA EDUCAÇÃO, 2007).

Projeto executados:

- Formação de Profissionais da Educação para a Cidadania e Diversidade Sexual 2005/2006;

- Diversidade Sexual e Igualdade de Gênero nas Escolas - 2006/2007;

- Educação e Gravidez na Adolescência;

- Gênero e Diversidade na Escola;

- Plano Nacional de Políticas para as Mulheres: articulação e monitoramento;
- Construindo a Igualdade de Gênero: prêmio para redações de estudantes do Ensino Médio (MINISTÉRIO DA EDUCAÇÃO, 2007).

No ano de 2011, a SECAD passa a ser nomeada de Secretaria de Educação Continuada, Alfabetização e Diversidade e Inclusão (SECADI), em razão dos crescentes debates em torno de ações afirmativas para a população negra, garantia de direitos à população carente, direito à educação pública e gratuita para todos - incluindo as pessoas jovens e adultas analfabetas.

Por meio do Decreto no 9.465, de 02 de janeiro de 2019 (BRASIL, 2019), a SECADI foi extinta por Vélez Rodriguez, ex-Ministro da Educação do Governo Jair Bolsonaro, constituindo um retrocesso no campo dos direitos educacionais, demonstrando as medidas de viés neoliberal tomadas pelo novo governo e a dimensão contrária do reconhecimento da diversidade e da necessidade de sua inclusão no processo educativo. Ações como essa já vinham sendo anunciadas pelo atual governo, antes mesmo de sua posse. Com uma agenda ultraconservadora, apoiando projetos extremistas que representam um retrocesso na conquista de direitos das minorias, a atual gestão do governo federal não reconhece a diversidade que constitui a população brasileira; suas ações vêm apontando para um declínio nas conquistas no âmbito das políticas públicas educacionais que visam ao reconhecimento da diversidade e à promoção das desigualdades no contexto social e, consequentemente, no escolar.

\section{Do retrocesso das políticas públicas educacionais de} gênero e diversidade sexual à ascensão do Movimento Escola sem Partido: um projeto de combate à diversidade

No ano de 2014, o Congresso Federal sancionou o Plano Nacional de Educação (PNE) com o intuito de direcionar esforços e investimentos 
para a melhoria da qualidade da educação no país. Com força de lei, o PNE estabelece 20 metas a serem atingidas nos próximos 10 anos. Desse modo, todos os estados e municípios nacionais ficam incumbidos de elaborar planejamentos específicos para firmar a obtenção dos objetivos previstos, considerando as demandas e necessidades locais.

Contudo, o PNE (2014-2020) vem se apresentado como um notável cenário para as manifestações conservadoras presentes no Congresso Nacional, com proeminência da bancada fundamentalista cristã. Logo inicia-se uma caçada a qualquer menção ou estratégia que abarcasse temáticas referentes a gênero e sexualidade no referido documento.

Em consequência, no texto final da lei que aprova o novo PNE, foram excluídos termos como homofobia, identidade de gênero, lesbofobia, machismo, movimento feminista, orientação sexual, segregação, sexismo, transfobia e outros que constavam anteriormente no documento final da Conferência Nacional da Educação (CONAE), sendo este o documento base para a elaboração do PNE (2014-2020). Situação em que observamos um grande retrocesso nos mínimos avanços alcançados com os PCNs, que em 1998 argumentava que:

Com a inclusão da Orientação Sexual nas escolas, a discussão de questões polêmicas e delicadas, como masturbação, iniciação sexual, o 'ficar' e o namoro, homossexualidade, aborto, disfunções sexuais, prostituição e pornografia, dentro de uma perspectiva democrática e pluralista, em muito contribui para o bem-estar das crianças, dos adolescentes e dos jovens na vivência de sua sexualidade atual e futura. (BRASIL, 1998, p. 293, grifo do autor).

Observamos que, apesar das consistentes críticas aos PCNs, esse documento norteador do currículo escolar no ano de 1998 mostrava-se mais aberto às questões da diversidade sexual e de gênero do que presenciamos nas orientações do atual PNE, em razão das pressões originárias de movimentos sociais e políticos conservadores. Em nota endereçada aos Prefeitos, Presidentes, Vereadores dos mu- nicípios e educadores e pais no estado de São Paulo, os bispos católicos do estado de São Paulo sugeriram que a elaboração dos Planos Municipais de Educação fossem orientados pelo PNE votado no Congresso Nacional em 2014, observando que as expressões da ideologia de gênero já tinham sido retiradas do referido documento nacional, sugerindo, então, que os municípios do estado de São Paulo seguissem na mesma direção. A nota apresenta que

\begin{abstract}
A ideologia de gênero subverte o conceito de família, que tem seu fundamento na união estável entre homem e mulher, ensinando que a união homossexual é igualmente núcleo fundante da instituição familiar. As consequências da introdução dessa ideologia na prática pedagógica das escolas contradizem frontalmente a configuração antropológica de família, fundamento insubstituível para a construção da sociedade. (CONFERÊNCIA NACIONAL DOS BISPOS DO BRASIL, 2015).
\end{abstract}

Prontamente, o termo "ideologia de gênero" é fortemente ratificado pelos representantes religiosos e pela imprensa do país, conforme afirma Carreira (2015, p. 375):

No contexto geral de fortalecimento do conservadorismo no país, a entrada da cúpula da Igreja Católica com maior protagonismo no processo dos planos municipais e estaduais de educação pode ser lida como mais um capítulo da disputa por hegemonia religiosa no país com o campo evangélico, visando a um eleitorado mais conservador em plena ascensão. Essa disputa por protagonismo diante de uma atuação evangélica de destaque em várias frentes conservadoras no Congresso Nacional, na qual se inclui o veto presidencial ao kit Escola sem Homofobia em 2011, representa um grande marco. Esse fato contribuiu para o fortalecimento de vários parlamentares evangélicos no Congresso Nacional.

Outro fato que contribuiu de forma efetiva para a fundamentação desse posicionamento conservador diante dessa temática e reforçou a atuação dos Protestantes no Congresso Nacional, foi a eleição do pastor da Igreja Batista, Marco Feliciano, na Comissão de Direitos Humanos da Câmara, em 2013, em razão de suas colocações nas redes sociais sobre africanos e 
homossexuais, como na pregação que realizou no 30 Congresso de Gideões Missionários da Última Hora, ocorrido em 2012, declarando a AIDS como um "câncer gay" (CONGRESSO INTERNACIONAL DE MISSÕES, 2012). Assim, nesse cenário, emergiram diversos discursos voltados para a criminalização da prática docente, apoiados por políticos ultraliberais ecoados por forças conservadoras. Contexto que favoreceu o surgimento de movimentos conservadores como a Escola sem Partido, que emerge acusando as escolas de praticarem uma educação doutrinária-ideológica, além de propor que os professores não expressem opiniões próprias. Ou seja, segundo o Movimento, não abusem da liberdade de ensinar.

O Movimento Escola sem Partido foi criado no ano de 2004 pelo advogado Miguel Nagib, obtendo, no início de 2010, maior destaque nos debates sobre educação no Brasil, transformando-se em projeto de lei no ano de 2015. Há duas vertentes de trabalho bem definidas: uma que trabalha com foco no Projeto Escola sem Partido $^{2}$ (PESP), que trata em específico dos projetos de lei apresentados em âmbito municipal, estadual ou federal que objetivam traçar as condutas a serem seguidas pelos professores em sala de aula; e outra que se constitui numa associação informal, composta por pais, alunos e conselheiros "preocupados com o grau de contaminação político-ideológico das escolas brasileiras, em todos os níveis: do ensino básico ao superior" (ESCOLA SEM PARTIDO, 2019).

No texto de apresentação sobre o movimento, assinado pelo coordenador Miguel Nagib, os professores são classificados como exército de militantes que se valem da liberdade de cátedra e da "cortina de segredo das salas de aula" (ESCOLA SEM PARTIDO, 2019) para impor algo indesejado aos alunos, constrangê-los com uma visão de mundo própria dos professores. Afinal, como aponta Frigotto (2017, p. 20), é através do golpe que a classe dominante brasileira objetiva deter "duas conquistas, ainda que

20 projeto apresenta orientações no website oficial www. programaescolasempartido.org. parciais, dos movimentos sociais, sindicatos, instituições científicas e culturais", que lutam por justiça social: "a Constituição de 1988 e a eleição, em 2002, do ex-operário Luiz Inácio Lula da Silva”. É nesse ínterim que o Movimento Escola Sem Partido se vale da bandeira educacional para tecer discursos que fragilizam as conquistas no campo escolar e, assim, sob a máscara de defesa da educação, produzir um discurso que não reconhece a heteronormatização que ocorre em nossa sociedade e a importância da escola frente ao combate ao preconceito de todos os tipos e formas.

Embora o Movimento Escola Sem Partido seja relativamente recente, há tempos a educação está no centro da disputa pela hegemonia dos que detêm o poder. Na década de 1960, em específico no período da Ditadura Militar no Brasil, as escolas e as universidades foram controladas pelo regime a fim de coibir e punir quaisquer ameaças comunistas, atitudes críticas e ações que porventura confrontassem o governo. As conquistas alcançadas em 1988, com a promulgação de uma Constituição Cidadã, com princípios democráticos, vêm sendo ameaçadas por movimentos fundamentalistas como a Escola Sem Partido.

O discurso autoritário e de censura que outrora circulava em nossa sociedade vem à tona no contexto político atual e não disfarçado, ou tentando assumir novos contrastes, pelo contrário, vale-se de uma agenda contra a escola pública, laica e que promova o debate social a partir da realidade dos próprios alunos. Conforme Frigotto (2017, p. 32),

0 que propugna o Escola sem Partido não liquida somente a função docente, no que a define substantivamente e que não se reduz a ensinar o que está em manuais ou apostilas, cujo propósito é de formar consumidores. A função docente no ato de ensinar tem implícito $o$ ato de educar. Trata-se de, pelo confronto de visões de mundo, de concepções científicas e de métodos pedagógicos, desenvolver a capacidade de ler criticamente a realidade e constituírem-se sujeitos autônomos. A pedagogia da confiança e do diálogo crítico é substituída pelo estabeleci- 
mento de uma nova função: estimular os alunos e seus pais a se tornarem delatores.

Nessa perspectiva, os ideais propagados pelo Movimento Escola sem Partido, em consonância com as práticas dos governos autoritários com ideologias bem definidas, são pautados no combate à doutrinação que, segundo eles, ocorre nas escolas, com vistas a uma educação sem viés ideológico e que não discuta a questão do gênero e da diversidade sexual.

Nesse ínterim, são notórias as diversas ações governamentais na tentativa de descontruir os projetos que foram gerados através de árduas lutas sociais para assegurar a garantia de direitos no que tange à questão de gênero e de diversidade sexual. As políticas públicas desenvolvidas ao longo dos anos a fim de assegurar a representatividade das minorias e, em específico, da comunidade LGBTQ+ vêm sendo desconstruídas no cenário político atual.

\section{Considerações finais}

O propósito deste estudo foi analisar as principais Políticas Públicas Educacionais de Gênero e Diversidade Sexual, suas ascensões e conquistas e os impasses e retrocessos sofridos frente ao avanço conservador do Movimento Escola Sem Partido. Observamos que, em todos os documentos analisados, a Educação é relacionada ao direito à cidadania e à construção de uma sociedade democrática, por meio do reconhecimento e da valorização da diversidade e dos direitos humanos. Mesmo apresentando controvérsias, revelam-se como avanços para a inserção dessa temática no ambiente escolar, proporcionando, ainda que timidamente, um espaço para discussão acerca de tais temas.

Contudo, é inegável que o processo de formulação de políticas públicas não é necessariamente neutro nem linear, ele é permeado por avanços e retrocessos, bem como é cercado por imprevisibilidades e improvisos. Não há como desconsiderar as diversas convergências de forças ideológicas, estruturas políticas e de gestão que perpassam esse processo. Sob essa égide, as políticas públicas desenvolvidas mostram-se muito mais como políticas públicas de governo do que políticas públicas de Estado. Ou seja, evidenciam-se como ações e projetos para atender às necessidades de projeção de determinados governos para satisfazer certos grupos sociais, permitindo, assim, que os mínimos avanços conquistados não permaneçam, mas abram espaços para os retrocessos que atendam às expectativas e aos anseios de grupos conservadores que estão mais interessados em legislar em favor de seus próprios interesses. De forma explícita, é notório esse processo na elaboração do atual Plano Nacional de Educação, na repercussão do Movimento Escola Sem Partido e no grande apoio que este Movimento vem recebendo do atual governo.

As mudanças nesse cenário só serão possíveis se o sistema educacional proporcionar condições para que as escolas possam ser palco de críticas e transformações sociais. Para que os alunos possam se tornar agentes dessa mudança e possam se emancipar, é preciso que assuntos que ameacem cercear direitos, tolher a liberdade dos cidadãos e sufocar a democracia sejam amplamente discutidos e sejam feitas análises críticas sobre eles. Só assim teremos uma educação transformadora e políticas públicas que se prestem ao atendimento das necessidades sociais, permanentes, como o Estado de direito; e não passageiras, como os governos partidários.

\section{REFERÊNCIAS}

BRASIL. Presidência da República. Casa Civil. Decreto $n^{\circ} 1.904$, de 13 de maio de 1996 . Institui o Programa Nacional de Direitos Humanos - PNDH. Brasília, DF, 1996. Disponível em: http://www. planalto.gov.br/ccivil_03/decreto/D1904.htm. Acesso em: 13 nov. 2019.

BRASIL. Ministério da Educação. Secretaria de Educação Fundamental. Parâmetros curriculares nacionais: ensino fundamental. Brasília, DF, 1997. Disponível em: http://portal.mec.gov.br. Acesso em: 13 nov. 2019.

BRASIL. Ministério da Educação. Secretaria de 
Educação Fundamental. Parâmetros Curriculares Nacionais: terceiro e quarto ciclos do ensino fundamental: introdução aos parâmetros curriculares nacionais. Brasília, DF: MEC/SEF, 1998.

BRASIL. Ministério da Educação. Secretaria de Educação Fundamental. Parâmetros Curriculares Nacionais: pluralidade cultural e orientação sexual. 3. ed. Brasília, DF: MEC/SEF, 2001a.

BRASIL. Presidência da República. Casa Civil. Decreto no 3.952, de 04 de outubro de 2001. Dispõe sobre o Conselho Nacional de Combate à Discriminação - CNCD. Brasília, DF, 2001b. Disponível em: https://www.planalto.gov.br/ ccivil_03/decreto/2001/d3952.htm. Acesso em: 13 nov. 2019.

BRASIL. Presidência da República. Casa Civil. Decreto no 4.229, de 13 de maio de 2002. Dispõe sobre o Programa Nacional de Direitos Humanos - PNDH, instituído pelo Decreto no 1.904, de 13 de maio de 1996, e dá outras providências. Brasília, DF, 2002. Disponível em: http://www.planalto.gov. br/ccivil_03/decreto/2002/D4229.htm. Acesso em: 13 nov. 2019.

BRASIL. Ministério da Saúde. Programa Brasil sem Homofobia: programa de combate à violência e à discriminação contra GLBT e de promoção da cidadania homossexual. Brasília, DF: Ministério da Saúde/Conselho Nacional de Combate à Discriminação, 2004. Disponível em: http:// bvsms.saude.gov.br/bvs/publicacoes/brasil_sem_ homofobia.pdf. Acesso em: 13 nov. 2019.

BRASIL. Presidência da República. Casa Civil. Decreto no 5.397, de 22 de março de 2005. Dispõe sobre a composição, competência e funcionamento do Conselho Nacional de Combate à Discriminação - CNCD. Brasília, DF, 2005. Disponível em: http://www.planalto.gov.br/ ccivil_03/_Ato2004-2006/2005/Decreto/D5397. htm. Acesso em: 13 nov. 2019.

BRASIL Ministério da Justiça. Secretaria Especial dos Direitos Humanos. Texto-Base da Conferência Nacional de Gays, Lésbicas, Bissexuais, Travestis e Transexuais. Brasília, DF: MJ/SEDH, 2008.

BRASIL. Ministério da Educação. Secretaria de Educação Continuada, Alfabetização e Diversidade. Gênero e diversidade na escola: formação de professoras/es em gênero, sexualidade, orientação sexual e relações étnico-raciais. Brasília, DF: MEC/ SECAD, 2009.

BRASIL. Presidência da República. Casa Civil. De- creto no 9.465, de 02 de janeiro de 2019. Aprova a Estrutura Regimental e o Quadro Demonstrativo dos Cargos em Comissão e das Funções de Confiança do Ministério da Educação, remaneja cargos em comissão e funções de confiança e transforma cargos em comissão do Grupo-Direção e Assessoramento Superiores - DAS e Funções Comissionadas do Poder Executivo - FCPE. Brasília, DF, 2019. Disponível em: https://www.conjur.com. br/dl/decreto-9465-janeiro-2019-ensino-militar. pdf. Acesso em: 13 nov. 2019.

CARDOSO, Zilmar Santos. Diretrizes curriculares para a educação das relações étnico raciais nos cursos de formação docentes: um estudo de caso da Lei 10.639/03 e seus desdobramentos legais. 2016. Tese (Doutorado em Ciências Sociais) - Universidade do Estado do Rio de Janeiro (UERJ), Rio de Janeiro, 2016.

CARREIRA, Denise. Gênero e educação: fortalecendo uma agenda para as políticas educacionais. São Paulo: Ação Educativa/Cladem/ Ecos/Gelédes/Fundação Carlos Chagas, 2015.

CONFERÊNCIA NACIONAL DOS BISPOS DO PRASIL (CNBB). Regional Sul 1 da CNBB. Nota do Regional Sul 1/CNBB sobre ideologia de gênero na educação. São Paulo, 2015. Disponível em: https://www. diocesedesantos.com.br/nota-do-regional-sul1cnbb-sobre-ideologia-de-genero-na-educacao/. Acesso em: 29 nov. 2019.

CONGRESSO INTERNACIONAL DE MISSÕES, 30., 2012, Camboriú, SC. Anais [...]. Tema: Gideões: unidos há três décadas na evangelização do mundo. Disponível em: http://ww.gideoes.com.br. Acesso em: 19 nov. 2019.

DOMINGOS, Cleverson de Oliveira. Gênero, sexualidade e diversidade nas políticas educacionais: um mapeamento preliminar das ações e documentos da Secretaria de Estado de Educação do Distrito Federal (2011-2014). In: CARVALHO, Pimentel Iracilda; ABREU, Fabrício Santos Dias de (org.). Diversidade no contexto escolar: problematizações a partir dos marcadores de gênero, sexualidade e raça. Curitiba: Appris, 2016. p. 119-138.

ESCOLA SEM PARTIDO. Quem somos. Sobre nós. Disponível em: http://www.escolasempartido.org/ quem-somos/. Acesso em: 28 nov. 2019.

FIGUEIRÓ, Mary Neide Damico. Educação sexual: retomando uma proposta, um desafio. Londrina, PR: EDUEL, 2001. 
FRIGOTTO, Gaudêncio. A gênese das teses do Escola sem Partido: esfinge e ovo da serpente que ameaçam a sociedade e a educação. In: FRIGOTTO, Gaudêncio (org.). Escola "sem" partido: esfinge que ameaça a educação e a sociedade brasileira. Rio de Janeiro: UERJ/LPP, 2017. p.17-34.

HENRIQUES, Ricardo et al. Gênero e diversidade sexual na escola: reconhecer diferenças e superar preconceitos. Brasília, DF, MEC/SECAD, 2007. (Coleção Cadernos SECAD, no 4).
MINISTÉRIO DA EDUCAÇÃO. Secretaria de Educação Continuada, Alfabetização e Diversidade. Gênero e diversidade sexual na escola: reconhecer diferenças e superar preconceitos. Brasília, DF: MEC/SECAD, 2007.

VIANNA, Claudia; UNBEHAUM, Sandra. Gênero na educação básica: quem se importa? Uma análise de documentos de políticas públicas no Brasil. Educação \& Sociedade, Campinas, SP, v. 27, n. 95, p. 407-428, maio/ago. 2006.

Recebido em: $15 / 03 / 2020$

Aprovado em: 09/06/2020 